\title{
Naltrexone in the Treatment of Broadly Defined Behavioral Addictions: A Review and Meta-Analysis of Randomized Controlled Trials
}

\author{
Fayçal Mouaffak ${ }^{a}$ Claudio Leite $^{a}$ Sonia Hamzaoui ${ }^{a} \quad$ Amine Benyamina $^{b}$ \\ Xavier Laqueille ${ }^{c}$ Oussama Kebir ${ }^{c, d}$ \\ aUnité de Psychiatrie d'Urgence, de Liaison et de Recherche, Pôle 93G04, EPS Ville Evrard, Saint Denis, \\ and ${ }^{b}$ Paul Brousse Hospital, Department of Addictology and Psychiatry, Université Paris-Sud, Villejuif, \\ 'Service d'Addictologie, Moreau de Tours, Centre Hospitalier Sainte-Anne, and ' Laboratory of Pathophysiology \\ of Psychiatric Diseases, Center for Psychiatry and Neurosciences, University Paris Descartes, Paris, France
}

\section{Keywords}

Behavioral addiction · Naltrexone $\cdot$ Opioid antagonist

\begin{abstract}
Introduction: Broadly defined behavioral addiction is a conceptual framework including behaviors characterized by loss of control and continuation despite significant negative consequences. Broadly defined behavioral addictions share many similarities with substance use disorders. As naltrexone is one of the most studied treatment for substance use disorders, we conducted a meta-analysis of randomized placebo-controlled trials (RCT) assessing the effectiveness of naltrexone in the treatment of broadly defined behavioral addictions. Method: We conducted a literature search and selection, up to January 1, 2017, according to previously set inclusion criteria. The selected trials underwent a quality assessment before data extraction and statistical analysis, which used fixed and random effects models. Standardized mean differences (SMD) were calculated using Hedge's adjusted g. Results: A total of 6 RCTs $(n=356)$ were included. Of these, 3 assessed naltrexone effectiveness in the treatment of pathological gambling, and 3 tested its benefits in broadly defined behavioral addictions other than pathological gambling (kleptomania, trichotillomania, and impulsive compulsive disorders). The meta-analysis of the whole sam-
\end{abstract}

\section{KARGER}

(C) 2017 S. Karger AG, Basel

E-Mail karger@karger.com

www.karger.com/ear ple resulted in a statistically significant score improvement under naltrexone versus placebo (fixed effect model: SMD = $-0.27,95 \% \mathrm{Cl}[-0.51$ to -0.03$], z=2.23 ; p=0.025)$. Conclusion: The results of our meta-analysis suggest a beneficial effect of naltrexone in the treatment of broadly defined behavioral addictions.

(c) 2017 S. Karger AG, Basel

\section{Introduction}

Broadly defined behavioral addictions can be defined "as a process whereby a behavior [...] is employed in a pattern characterized by loss of control and continuation despite significant negative consequences [...]" [1]. Their lifetime prevalence rates were estimated at 0.5-6\% [2-4]. They share many clinical characteristics and neurobiological underpinnings with substance use disorders (i.e., tolerance, withdrawal, and relapse) [5]. While pathological gambling was included in the addiction realm for Diagnostic and Statistical Manual of Mental Disorders version 5 (DSM-5), other behaviors such as kleptomania, hypersexual disorder, trichotillomania, skin picking disorder, compulsive buying, and impulse control disorder in Parkinson disease were not, as research on these disorders was deemed insufficient [6]. 
Beyond phenomenological and neurobiological similarities between broadly defined behavioral addictions and substance use disorders [7], therapeutic response of these conditions to anti-addiction medications would constitute a major further proof to characterize them as addictions. The pharmacological approach to treat substance use disorders consists in modulating reward mechanisms with medications that alter mesolimbic circuits via glutamatergic, serotonergic, dopaminergic, and opioidergic transmissions [8-10]. One of the most well studied medications used for treating behavioral addictions is naltrexone. Synthesized in 1963, naltrexone is a nonspecific competitive opioid antagonist with high affinity to $\mu$-opioid receptors in the central nervous system [11]. It has been approved by several regulatory bodies for opiates addictions and alcohol use disorder [12]. Its main effect appears to be a reduction in the pleasurable effects from drinking alcohol and, for some, the euphoria and craving for opiates. Although no medications were approved for the treatment of broadly defined behavioral addictions, naltrexone is commonly recommended and utilized in the treatment of pathological gambling, kleptomania, trichotillomania, and other disorders $[12,13]$. To our knowledge, no formal meta-analysis of the available data issued from randomized placebo-controlled trials (RCTs) of naltrexone in behavioral addictions has been conducted. In order to assess the relevance of this therapeutic option, we conducted a review of the literature and a meta-analysis of available data from RCTs of naltrexone in the treatment of behavioral addictions.

\section{Methods}

\section{Study Design}

The present meta-analysis adheres to the Preferred Reporting Items for Systematic Reviews and Meta-analyses statement [14].

\section{Search Strategy}

Our research question was "is naltrexone effective in treating broadly defined behavioral addictions?" To answer this question, we meta-analyzed available RCTs. A comprehensive literature search was performed to find studies, published up to January 1, 2017, on PubMed Medline, Web of Science, and ClinicalTrials.gov using combined free text searching with keywords probing. Our key search terms were "behavioral addictions," "binge eating disorder," "gambling disorder," "kleptomania," "trichotillomania," "hair pulling," "skin picking," “excoriation," "impulsive compulsive," "hypersexual disorder," "hypersexuality," "pathological buying," "internet gaming addiction," "opioid antagonists," and "naltrexone." Reference lists from the resulting publications and reviews were used, when possible, to identify further relevant publications. We subsequently checked articles according to inclusion criteria.

Naltrexone in Behavioral Addiction
Inclusion and Exclusion Criteria

To be included, studies had to fulfill the following criteria: (1) a randomized double blind placebo controlled design; (2) participants diagnosed according to the DSM version III, III-TR, IV, IVTR or 5, and/or the ICD-10 as suffering from gambling disorder, kleptomania, trichotillomania (hair pulling disorder), binge eating disorder, excoriation (skin picking disorder); (3) efficacy evaluation and outcome reporting rated in a continuous form able to be synthetized in meta-analysis. Exclusion criteria were as follows: (1) unavailable or incomplete data; (2) not reported outcome indexes; (3) noninterventional studies (e.g., case controls, case series, case controls, and cohorts); (4) nonoriginal studies (e.g., editorials, letters, reviews, and meta-analysis).

\section{Data Extraction}

Data extraction was performed separately by 2 authors (C.L. and O.K.) using a standardized form, collecting information on the study design, treatment used, characteristics of the sample, number of participants, and pre- and post-treatment scores on outcome measures. Authors were contacted, when necessary, for missing or incomplete data.

\section{Assessment of Study Quality}

The Jadad et al. [15] scale was used to assess the quality of each study. Criteria of high quality and low quality of included studies were defined as Jadad score $\geq 3$ or $<3$, respectively.

\section{Statistical Analysis}

We used fixed effects and random effects models to perform the statistical analysis [5]. Standardized mean difference estimates were calculated using Hedge's adjusted $g$. Heterogeneity was evaluated using the $\mathrm{I}^{2}$ statistic and values $>50 \%$ were considered as indicative of a large heterogeneity [6]. Funnel plots were used to calculate risk of bias and forest plots were generated to show standardized mean difference with $95 \%$ CI for each study. A total of 3 meta-analyses were conducted on total scores. Analyses were performed using MIX 2.0 Professional software for meta-analysis in Excel, version (2.0.1.5), BiostatXL, 2016 [16, 17].

\section{Results}

\section{Study Inclusion}

Our initial search on databases identified 948 studies. After duplicates removal, 903 studies were retained for title, abstract, and keywords screening. Of these, 876 were excluded and 27 left for full text eligibility assessment. Ultimately, we were left with 6 studies that fully satisfied the pre-established inclusion criteria (Fig. 1).

\section{Study Characteristics}

A total of 356 patients were included in 6 RCTs. The trial durations ranged from 8 to 20 weeks. Participants age was $40 \pm 11.4$ years, and 195 were men $(54.75 \%)$. The completers were 281 (79\%). Of these, 75 patients discontinued in the 2 arms, 51 in the intervention group and 14 
Fig. 1. PRISMA flowchart.

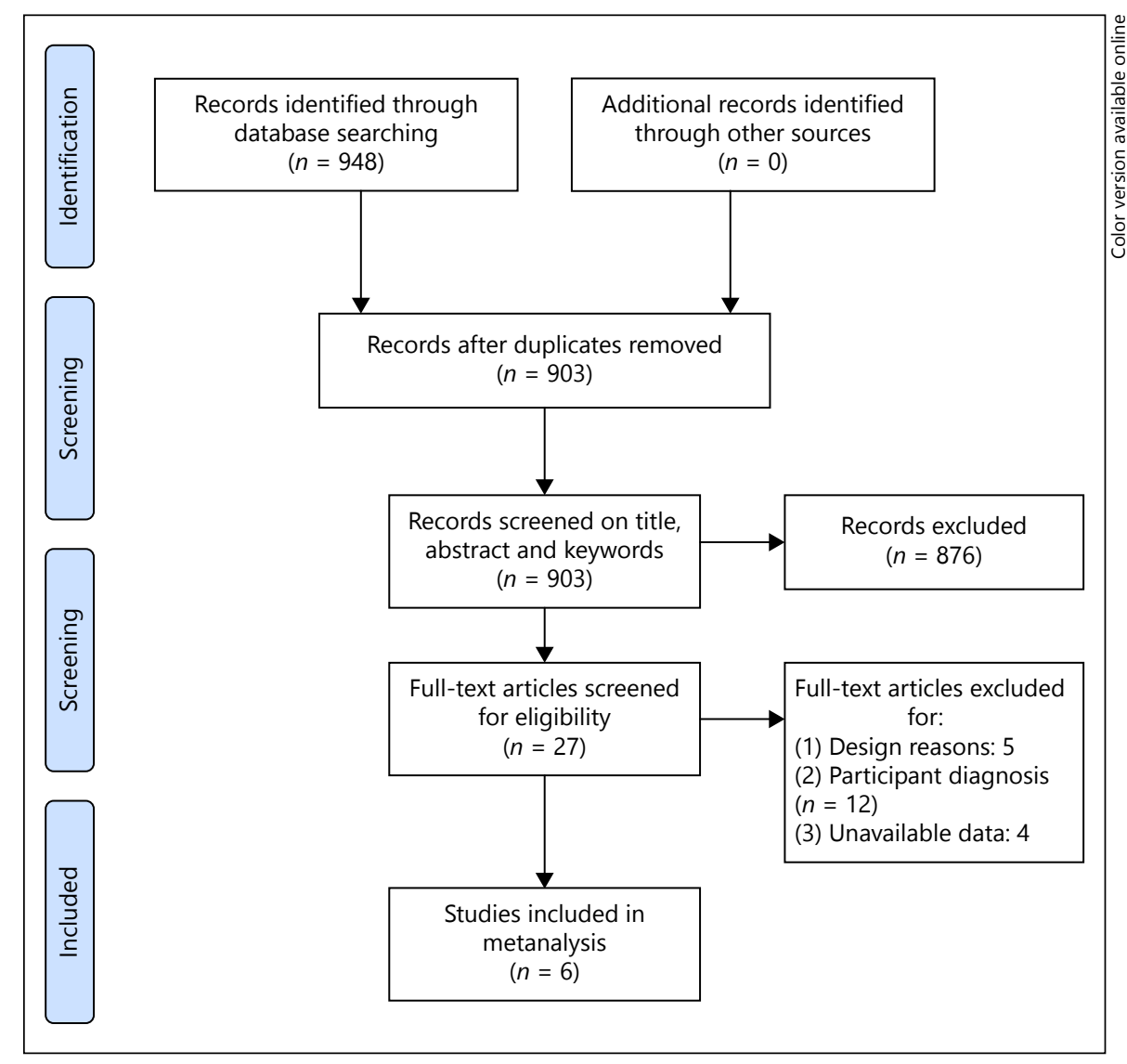

in the placebo group. The mean effective dose was reported in only 2 studies $[18,19], 100 \pm 39.4$ and $116.7 \pm 44.4$ $\mathrm{mg} /$ day, respectively. Naltrexone was administered as needed in only one study [20]. In the remaining trials, treatment dose ranged from 50 to $150 \mathrm{mg} /$ day.

Quality Assessment and Risk of Bias

All the selected studies mentioned randomization and used a computer generated technique. Only one study did not report its blinding method [19]. All but one study [21] reported on the reasons for withdrawal in each group. Regarding selective reporting, half of the studies did not use a protocol registration. According to Jadad scale [15], all the studies were rated as high quality trials.

\section{Statistical Analysis}

Naltrexone for Pathological Gambling

A total of 3 double-blind RCTs were analyzed [18, 20, 22], comprising 167 individuals with a diagnosis of pathological gambling. A total of 94 individuals were treated with naltrexone while 73 individuals received a placebo.
Study duration varied from 11 to 20 weeks. Naltrexone dosage varied from 50 to $150 \mathrm{mg}$ per day. In the 3 studies included, the primary outcome was the score improvement in Pathological Gambling adaptation of the Yale Brown obsessive compulsive scale in 2 studies [20, 22] and in gambling frequency in last month in the third study [18]).

Naltrexone induced a nonstatistically significant score improvement than placebo (low heterogeneity: $\mathrm{I}^{2}=0 \%$, $\mathrm{Q}=1.47, p=0.48$; fixed effects model: standardized mean differences [SMD] $=-0.22,95 \%$ CI $[-0.53$ to 0.09$], \mathrm{z}=$ $1.39, p=0.16)$.

Naltrexone for Broadly Defined Behavioral Addictions Other than Pathological Gambling A total of 3 double-blind RCTs [19, 21, 23] were analyzed, comprising 112 individuals with a diagnosis of kleptomania, trichotillomania, or impulse control disorders in Parkinson disease. A sum of 53 individuals were treated with naltrexone and 59 individuals received a placebo. Study duration was 8 weeks for the 3 RCTs. Naltrexone dosage varied from 50 to $150 \mathrm{mg}$ per day. In the 3 
Table 1. Characteristics of studies included in the meta-analysis

\begin{tabular}{|c|c|c|c|c|c|c|}
\hline Study & Kovanen, 2016 & Papay, 2014 & Grant, 2014 & Toneatto, 2009 & Grant, 2009 & Grant 2008 \\
\hline $\begin{array}{l}\text { Number of patients } \\
\text { baseline }\end{array}$ & $\begin{array}{l}\text { I: } 50 \\
\text { C: } 51\end{array}$ & $\begin{array}{l}\text { I: } 26 \\
\text { C: } 24\end{array}$ & $\begin{array}{l}\text { I: } 25 \\
\text { C: } 26\end{array}$ & $\begin{array}{l}\text { I: } 27 \\
\text { C: } 25\end{array}$ & $\begin{array}{l}\text { I: } 12 \\
\text { C: } 13\end{array}$ & $\begin{array}{l}\text { I: } 58 \\
\text { C: } 19\end{array}$ \\
\hline $\begin{array}{l}\text { Number of patients } \\
\text { endpoint }\end{array}$ & $\begin{array}{l}\text { I: } 32 \\
\text { C: } 37\end{array}$ & $\begin{array}{l}\text { I: } 22 \\
\text { C: } 23\end{array}$ & $\begin{array}{l}\text { I: } 20 \\
\text { C: } 24\end{array}$ & $\begin{array}{l}\text { I: } 26 \\
\text { C: } 25\end{array}$ & $\begin{array}{l}\text { I: } 11 \\
\text { C: } 12\end{array}$ & $\begin{array}{l}\text { I: } 36 \\
\text { C: } 13\end{array}$ \\
\hline Number of drop outs & $\begin{array}{l}\text { I: } 18 \\
\text { C: } 14\end{array}$ & $\begin{array}{l}\text { I: } 4 \\
\text { C: } 1\end{array}$ & $\begin{array}{l}\text { I: } 5 \\
\text { C: } 2\end{array}$ & $\begin{array}{l}\text { I: } 1 \\
\text { C: } 0\end{array}$ & $\begin{array}{l}\text { I: } 1 \\
\text { C: } 1\end{array}$ & $\begin{array}{l}\text { I: } 22 \\
\text { C: } 6\end{array}$ \\
\hline Analysis & ITT & ITT & ITT & ITT & ITT & ITT \\
\hline Trial duration, weeks & 20 & 8 & 8 & 11 & 8 & 18 \\
\hline Gender, males, \% & 68 & 68 & 13.7 & 93 & 18 & 40 \\
\hline Age, years mean \pm SD & $45.9 \pm 15.2$ & $61.2 \pm 8.5$ & $32.7 \pm 9.8$ & 40 & $34.3 \pm 12.1$ & $46.2 \pm 9.6$ \\
\hline Diagnosis & $\begin{array}{l}\text { Pathological } \\
\text { gambling }\end{array}$ & $\begin{array}{l}\text { Impulsive compulsive } \\
\text { disorder }\end{array}$ & Trichotillomania & $\begin{array}{l}\text { Adult alcohol abusing } \\
\text { Pathological gambling }\end{array}$ & Kleptomania & $\begin{array}{l}\text { Pathological } \\
\text { gambling }\end{array}$ \\
\hline Outcome & PG-YBOCS & QUIP-RS & MGH-HPS & $\begin{array}{l}\text { Gambling frequency } \\
\text { during last month }\end{array}$ & K-YBOCS & PG-YBOCS \\
\hline JADAD score & 5 & 5 & 4 & 5 & 4 & 5 \\
\hline
\end{tabular}

C, controls; D, discontinuing; ITT, intention to treat; I, intervention; K-YBOCS, kleptomania adaptation of the Yale Brown obsessive compulsive scale; MGH-HPS, Massachusetts General Hospital Hair Pulling Scale; NTX, naltrexone; PG-YBOCS, Pathological Gambling adaptation of the Yale Brown obsessive compulsive scale; QUIP-RS, Questionnaire for Impulsive Compulsive Disorders in Parkinson's Disease-Rating Scale.

studies included, the primary outcome was the score improvement on Kleptomania adaptation of the Yale Brown obsessive compulsive scale for kleptomania [19], the Massachusetts General Hospital Hair Pulling Scale (MGH-HPS) for trichotillomania [21], and the Questionnaire for Impulsive Compulsive Disorders in Parkinson's Disease-Rating Scale (QUIP-RS) [23].

Naltrexone induced a non-statistically significant score improvement than placebo (low heterogeneity: $\mathrm{I}^{2}=$ $60 \%, \mathrm{Q}=5, p=0.08$; fixed effects model: $\mathrm{SMD}=-0.35$, $95 \%$ CI [ -0.72 to 0.02$], \mathrm{z}=1.81, p=0.07)$.

\section{Naltrexone for Broadly Defined Behavioral}

\section{Addictions}

A total of 356 patients suffering from broadly defined behavioral addictions were randomized to receive either naltrexone $(n=198)$ or placebo $(n=158$; Table 1$)$. A sum of 291 participants completed the study, 147 in the naltrexone arm and 144 in the placebo arm. Outcome data were available for 279 patients ( 147 from the naltrexone arm and 132 in the placebo group). Study duration varied from 8 to 20 weeks. Naltrexone dosage varied from 50 to $150 \mathrm{mg}$ per day. The outcome was the score improvement of the Pathological Gambling adaptation of the Yale Brown obsessive compulsive scale in 2 studies [20,22], gambling frequency in last month [18], Kleptomania adaptation of the Yale Brown obsessive compulsive scale for kleptomania [19], MGH-HPS for trichotillomania [21], and QUIP-RS for impulse control disorders in Parkinson disease [23].

Naltrexone induced a statistically significant score improvement than placebo (heterogeneity: $\mathrm{I}^{2}=25.6 \%, \mathrm{Q}=$ 6.7, $p=0.24$; fixed effects model: $\mathrm{SMD}=-0.27,95 \% \mathrm{CI}$ [-0.51 to -0.03$], \mathrm{z}=2.23 ; p=0.025)$. Inspection of the forest plot (Fig. 2) indicates that the main global effect could be mainly driven by (Grant et al. [19]) data. A complementary sensitivity analysis by removing studies one by one was conducted. The global effect does not reach significance when data from any of the following 3 studies were dropped, respectively: Grant et al. [19] (SMD = $-0.19 ; p=0.12)$, Kovanen et al. [20] $(\mathrm{SMD}=0.25, p=$ $0.078)$, and Grant et al. [22] (SMD $=-0.26, p=0.052)$. 


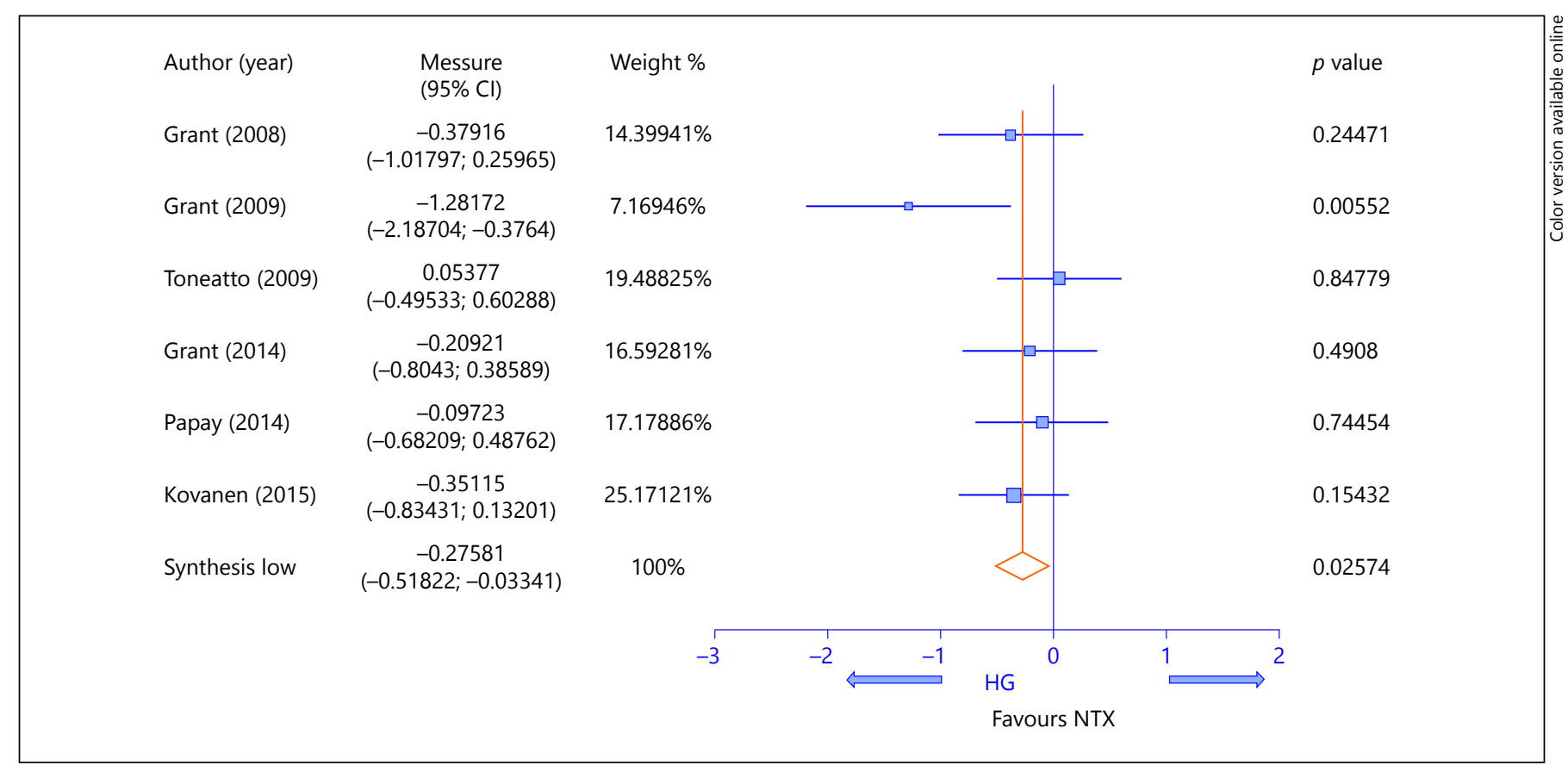

Fig. 2. Synthesis forest plot of meta-analysis under fixed effect model.

\section{Discussion}

Meta-analysis of the 3 controlled trials in pathological gambling $[18,20,22]$ concluded to a nonstatistically significant improvement under naltrexone compared to placebo. Similarly, the meta-analysis of the 3 RCTs involving patients suffering from kleptomania, trichotillomania, and impulse control disorders $[19,21,23]$ resulted in a nonsignificant improvement under naltrexone. By contrast, meta-analysis of the data gathered from the 6 RCTs suggested that the estimated benefit of naltrexone compared to placebo, although small, was statistically significant. Based on data issued from 6 published RCTs, this meta-analysis is, to our knowledge, the first one suggesting that naltrexone could be a beneficial treatment in broadly defined behavioral addictions.

Notwithstanding, a number of shortcomings should be mentioned. First, the heterogeneity of outcome measures is a limitation. While 3 studies $[19,21,22]$ used adaptations of the Y-BOCS to assess kleptomania and pathological gambling, 1 study used a validated measure of daily frequency and quantity of addictive behavior (time line follow back) [18]. The analyzed data from the 2 remaining studies [21, 23] were extracted from selfrated questionnaires, the MGH-HPS and QUIP-RS. Second, in 2 studies, participants received psychosocial in- terventions [20] and cognitive behavioral therapy sessions [18] that may have obscured any differences attributable to the medication. The absence, in these studies, of a nontreatment control group precluded the elimination of nonspecific therapeutic variables. In an earlier RCT [24], not included in our review for lack of data, the authors tested naltrexone effectiveness against placebo in pathological gambling. One quarter of the enrolled patients ( 22 on 83 ) responded to a 1 week placebo run-in phase. In our meta-analysis, only 2 trials conducted a 1 week placebo lead-in period, which resulted in the response of 6 patients ( $7.2 \%$ of the participants) in the first study [22] and only one patient in the second trial [18]. Although disparate, the rate of placebo responders raises the methodological issue of using longer duration run-in placebo phase systematically in such trials, where expected effect size is small and number of patients is limited. Third, included studies are sparse and of small sample size; thus, the generalizability of their results is limited.

Our results are in part similar to the findings of a prior meta-analysis [25] assessing the benefit of opiate antagonists ( 3 naltrexone and 2 nalmefene studies) on pathological gambling. The results significantly favored opiate antagonists $\left(\mathrm{I}^{2}=0 \%, \mathrm{SMD}=0.18\right)$. In our meta-analysis, the smaller sample size of the included studies probably 
precluded the detection of such a significant effect on pathological gambling.

Since its approval by the Food and Drug Administration in 1995, the recommended naltrexone dose in alcohol dependence is $50 \mathrm{mg}$ per day [12]. However, clinical data suggest that naltrexone high doses (up to $150 \mathrm{mg}$ per day) are of greater effectiveness in broadly defined behavioral addictions [26]. In our review, although the majority of participants had received doses higher than $50 \mathrm{mg}$ per day, no severe adverse effects have been reported. Naltrexone has low affinity at $\kappa$ receptors in the brain and spinal cord and little to no activity at $\delta$ receptors in the spinal cord and peripheral nervous system [27]. Actually, pharmacological studies, established that $95 \%$ of cerebral $\mu$ receptors are occupied after an oral dose of $50 \mathrm{mg}$ while only partial inhibition is produced on $\delta$ receptors [28]. As higher doses than $50 \mathrm{mg}$ per day are needed to produce inhibition of $\delta$ receptors [28], we could speculate that these receptors can play a critical role in naltrexone effect in broadly defined behavioral addictions treatment.

Our meta-analysis beyond suggesting a possible benefit of naltrexone in broadly defined behavioral addictions adds to the arguments supporting the idea that such behaviors should be considered as addictions. Neurocognitive research has yielded valuable data on the role of impulsivity, a trait that has been linked to both substance use disorders and broadly defined behavioral addictions; actually, the latter are in part referred to as impulsive compulsive disorder in DSM-5. The impulsivity that seems to characterize addiction may be caused by disruptions within the opioid system. Mouse $\mu$ receptor knockout models show remarkably decreased motor impulsiv- ity [29] and higher $\mu$ receptor availability has been associated with greater impulsivity [30]. Hence, naltrexone, as $\mu$ receptor antagonist, through reducing impulsivity may be effective across a rather broad spectrum of addictions involving both broadly defined behavioral addictions and substance use disorders.

Although a growing body of evidence suggests its relative safety and effectiveness, naltrexone remains an underutilized treatment option [12]. Given the high morbidity associated with addiction and the lack of alternate therapeutic strategies [12], further studies with longer duration, higher doses, and more methodological accuracy should be conducted in order to confirm or infirm the relevance of naltrexone in the treatment of broadly defined behavioral addictions. Analyzing studies using nalmefene, another recently marketed $\mu$ antagonist but lesser investigated than naltrexone could also improve our understanding of the role of the opioid neurotransmission in the pathophysiology of addictive disorders.

\section{Disclosure Statement}

All authors have no conflicts of interest.

\section{Authors Contributors}

All the authors were involved in the study design, had full access to the survey data and analyses, and interpreted the data, critically reviewed the manuscript, and had full control, including final responsibility for the decision to submit the paper for publication.

\section{References}

1 Goodman A: Addiction: definition and implications. Br J Addict 1990;85:1403-1408.

2 Christenson GA, Pyle RL, Mitchell JE: Estimated lifetime prevalence of trichotillomania in college students. J Clin Psychiatry 1991;52: 415-417.

3 Bohne A, Wilhelm S, Keuthen NJ, Baer L, Jenike MA: Skin picking in German students. Prevalence, phenomenology, and associated characteristics. Behav Modif 2002;26:320-339.

4 Grant JE, Schreiber LR, Odlaug BL: Phenomenology and treatment of behavioural addictions. Can J Psychiatry 2013;58:252-259.

5 Grant JE, Brewer JA, Potenza MN: The neurobiology of substance and behavioral addictions. CNS Spectr 2006;11:924-930.

6 Grant JE, Chamberlain SR: Expanding the definition of addiction: DSM-5 vs. ICD-11. CNS Spectr 2016;21:300-303.
7 Potenza MN: Should addictive disorders include non-substance-related conditions? Addiction 2006;101(suppl 1):142-151.

8 Hou H, Tian M, Zhang H: Positron emission tomography molecular imaging of dopaminergic system in drug addiction. Anat Rec (Hoboken) 2012;295:722-733.

9 O'Brien CP, Gastfriend DR, Forman RF, Schweizer E, Pettinati HM: Long-term opioid blockade and hedonic response: preliminary data from two open-label extension studies with extended-release naltrexone. Am J Addict 2011;20:106-112.

10 Porchet RI, Boekhoudt L, Studer B, Gandamaneni PK, Rani N, Binnamangala S, Müller U, Clark L: Opioidergic and dopaminergic manipulation of gambling tendencies: a preliminary study in male recreational gamblers. Front Behav Neurosci 2013;7:138.
11 Niciu MJ, Arias AJ: Targeted opioid receptor antagonists in the treatment of alcohol use disorders. CNS Drugs 2013;27:777787

12 Aboujaoude E, Salame WO: Naltrexone: a pan-addiction treatment? CNS Drugs 2016; 30:719-733.

13 Piquet-Pessôa M, Fontenelle LF: Opioid antagonists in broadly defined behavioral addictions: a narrative review. Expert Opin Pharmacother 2016;17:835-844.

14 Liberati A, Altman DG, Tetzlaff J, Mulrow C, Gøtzsche PC, Ioannidis JP, Clarke M, Devereaux PJ, Kleijnen J, Moher D: The PRISMA statement for reporting systematic reviews and meta-analyses of studies that evaluate health care interventions: explanation and elaboration. J Clin Epidemiol 2009;62:e1e34. 
15 Jadad AR, Moore RA, Carroll D, Jenkinson C, Reynolds DJ, Gavaghan DJ, McQuay HJ: Assessing the quality of reports of randomized clinical trials: is blinding necessary? Control Clin Trials 1996;17:1-12.

16 Bax L, Yu LM, Ikeda N, Tsuruta H, Moons KG: Development and validation of MIX: comprehensive free software for meta-analysis of causal research data. BMC Med Res Methodol 2006;6:50.

17 Bax L, Yu LM, Ikeda N, Moons KG: A systematic comparison of software dedicated to meta-analysis of causal studies. BMC Med Res Methodol 2007;7:40.

18 Toneatto T, Brands B, Selby P: A randomized, double-blind, placebo-controlled trial of naltrexone in the treatment of concurrent alcohol use disorder and pathological gambling. Am J Addict 2009;18:219-225.

19 Grant JE, Kim SW, Odlaug BL: A doubleblind, placebo-controlled study of the opiate antagonist, naltrexone, in the treatment of kleptomania. Biol Psychiatry 2009;65:600606.

20 Kovanen L, Basnet S, Castrén S, Pankakoski M, Saarikoski ST, Partonen T, Alho H, Lahti T: A randomised, double-blind, placebo-con- trolled trial of as-needed naltrexone in the treatment of pathological gambling. Eur Addict Res 2016;22:70-79.

21 Grant JE, Odlaug BL, Schreiber LR, Kim SW: The opiate antagonist, naltrexone, in the treatment of trichotillomania: results of a double-blind, placebo-controlled study. J Clin Psychopharmacol 2014;34:134-138.

22 Grant JE, Kim SW, Hartman BK: A doubleblind, placebo-controlled study of the opiate antagonist naltrexone in the treatment of pathological gambling urges. J Clin Psychiatry 2008;69:783-789.

23 Papay K, Xie SX, Stern M, Hurtig H, Siderowf A, Duda JE, Minger J, Weintraub D: Naltrexone for impulse control disorders in Parkinson disease: a placebo-controlled study. Neurology 2014;83:826-833.

24 Kim SW, Grant JE, Adson DE, Shin YC, Toth JA: A double-blind, placebo-controlled study of naltrexone in the treatment of pathological gambling disorder. Biol Psychiatry 2000;47: 166S-166S.

25 Bartley CA, Bloch MH: Meta-analysis: pharmacological treatment of pathological gambling. Expert Rev Neurother 2013;13:887894.
26 Kim SW: Opioid antagonists in the treatment of impulse-control disorders. J Clin Psychiatry 1998;59:159-164.

27 Wentland MP, Lou R, Lu Q, Bu Y, Denhardt C, Jin J, Ganorkar R, VanAlstine MA, Guo C, Cohen DJ, Bidlack JM: Syntheses of novel high affinity ligands for opioid receptors. Bioorg Med Chem Lett 2009;19:2289-2294.

28 Weerts EM, Kim YK, Wand GS, Dannals RF, Lee JS, Frost JJ, McCaul ME: Differences in delta- and mu-opioid receptor blockade measured by positron emission tomography in naltrexone-treated recently abstinent alcohol-dependent subjects. Neuropsychopharmacology 2008;33:653-665.

29 Olmstead MC, Ouagazzal AM, Kieffer BL: $\mathrm{Mu}$ and delta opioid receptors oppositely regulate motor impulsivity in the signaled nose poke task. PLoS One 2009;4:e4410.

30 Mick I, Myers J, Ramos AC, Stokes PR, Erritzoe D, Colasanti A, Gunn RN, Rabiner EA, Searle GE, Waldman AD, Parkin MC, Brailsford AD, Galduroz JC, Bowden-Jones H, Clark L, Nutt DJ, Lingford-Hughes AR: Blunted endogenous opioid release following an oral amphetamine challenge in pathological gamblers. Neuropsychopharmacology 2016;41:1742-1750. 